\title{
Anomalous Internal Carotid Anastomosis to Contralateral Anterior Cerebral Artery
}

\author{
Yasuo Murai, Yukio Ikeda, Hidetaka Sato, \\ Yasuhiro Yamamoto, Akira Teramoto
}

\begin{abstract}
Background: Many anomalies and variants in vascular anatomy have been reported in relation to the anterior cerebral artery (ACA). Patients and Methods: We encountered an apparently novel anomaly in a 30-year-old man admitted for disturbance of consciousness following a traffic accident. Computed tomography revealed an acute subdural hematoma and subarachnoid hemorrhage. Results and conclusions: No vascular abnormalities related to the hemorrhage were detected by conventional angiography, so we concluded that the bleeding was of traumatic origin. Anomalous origin of the ACA was disclosed incidentally, with both A1 segments arising from the right internal carotid artery; no normal A1 segment of the left ACA was visualized. We discuss possible bases for this anomalous origin.
\end{abstract}

RÉSUMÉ: Anastomose d'une carotide interne anormale à l'artère cérébrale antérieure controlatérale. Introduction: Plusieurs anomalies et variantes de l'anatomie vasculaire de l'artère cérébrale antérieure (ACA) ont été rapportées. Patients et méthodes: Nous avons rencontré une nouvelle anomalie chez un homme de 30 ans admis pour altération de l'état de conscience suite à un accident de la route. La tomographie assistée par ordinateur a montré un hématome sous-dural aigu. Aucune anomalie vasculaire reliée à l'hémorragie n'a été détectée par angiographie conventionnelle. Nous avons donc conclu que le saignement était d'origine traumatique. Résultats $\boldsymbol{e t}$ conclusions: L'origine anormale de l'ACA a été une découverte fortuite. Les deux segments A1 de l'ACA gauche prenaient naissance à la carotide interne droite et aucun segment A1 normal n'a été visualisé. Nous discutons des causes possibles de cette anomalie.

Can. J. Neurol. Sci. 2005; 32: 359-360

Vascular anomalies involving the anterior portion of the circle of Willis are common. ${ }^{1-3}$ Fenestration ${ }^{4,5}$ or duplication ${ }^{1,3,4}$ of the anterior cerebral artery (ACA) is a frequent incidental finding in cerebral angiograms. Aplasia and hypoplasia of the A1 segment also are reported frequently. ${ }^{1,3}$ However, internal carotid artery (ICA) anastomosis with the contralateral ACA is unusual. We encountered an extremely rare variant of such an anastomosis.

\section{CASE REPORT}

A 30-year-old man with disturbance of consciousness after a traffic accident was admitted to our department. Computed tomography performed on admission revealed a subdural hematoma and subarachnoid hemorrhage in the interhemispheric fissure. Since no craniofacial injury was apparent, we performed conventional angiography to identify a source of hemorrhage. No aneurysm or arteriovenous malformation was detected by angiography, so we diagnosed the patient with traumatic hemorrhage. Incidentally, however, a vascular variant was detected (Figure), involving an anomalous origin of the ACA. The origin and course of both A1 segments were consistent with unilateral origin from the right internal carotid artery. The A1 segment of the left ACA was not visualized. We treated the intracranial hematoma conservatively, and the patient was discharged with no neurologic deficit.

\section{Discussion}

The A1 segment of the ACA is the most frequent site of anatomic variation in the circle of Willis. ${ }^{1-6}$ Variations within the anterior communicating artery with complexes including duplication, ${ }^{2,6-8}$ azygos ACA, 2,4,8 or accessory ACA are extremely common; ${ }^{2,8}$ with some degree of asymmetry between the two A1 segments being identifiable in approximately $80 \%$ of patients undergoing arteriography. ${ }^{2}$ Several different

From the Department of Neurosurgery and Critical Care Medicine (YM, HS, YY, AT), Nippon Medical School, Tokyo, Japan; Department of Neurosurgery (YI), Hachioji Medical Center of Tokyo Medical University, Toyko, Japan

Received OCtober 5, 2004. ACCEPTED IN FINAL FORM March 22, 2005.

Reprint requests to: Yasuo Murai, Department of Neurosurgery, Nippon Medical School, 1-1-5 Sendagi, Bunkyo-ku, Toyko 113-8603, Japan. 

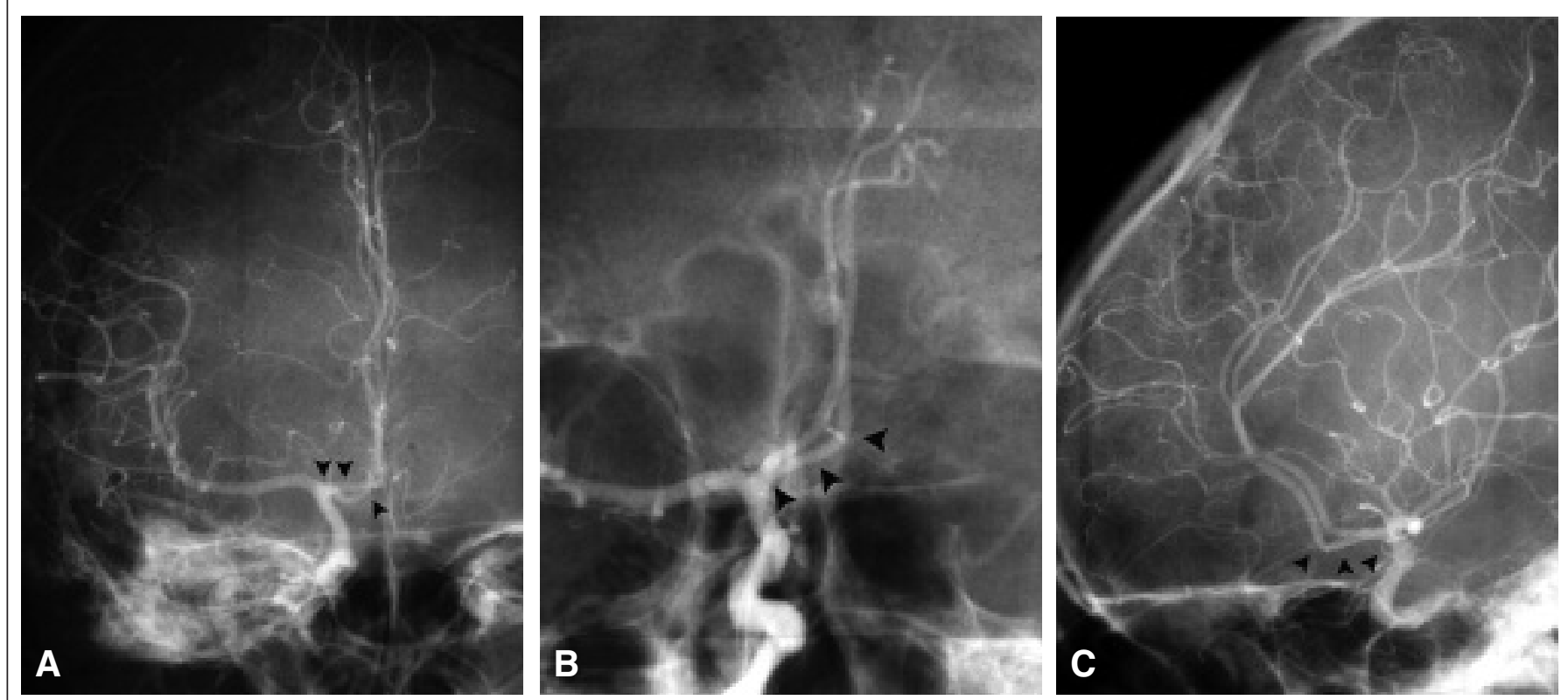

Figure: Cerebral angiogram performed via the right common carotid artery, including anteroposterior (A), left oblique (B), and lateral (C) projections. The branches of the left anterior cerebral artery originate from the right internal carotid artery (arrowheads).

combinations of anomalies have been observed, including hypoplastic or aplastic arteries, ${ }^{3,5,8}$ and fenestration ${ }^{4,5}$ of the A1 segments. Proposed embryologic events resulting in these anomalies remain matters of controversy. ${ }^{1,-6,8}$ In some less common anomalous vessels, such as infra-optic course of ACA, supra-optic duplication, perioptic duplication, or accessory middle cerebral artery, branches receive blood from the ipsilateral artery. ${ }^{8}$ In distinction, we demonstrated a contralateral ICA-to-ACA anastomosis by cerebral angiography, which we believe to be the first reported case identified in this manner. This general type of anomaly first was described in postmortem dissections by Baptista in $1963,{ }^{1}$ whose descriptions indicated that our case would represent a "bihemispheric ACA" or a "crossed-branch type" of anomaly. Baptista ${ }^{1}$ suggested that during embryonic development one of three arteries (either ACA or the median artery of the corpus callosum) had developed insufficiently, while another hypertrophied to result in a constant blood supply. Considering anomalies of the anterior cerebral artery, detected in examinations of 381 brains, Baptista ${ }^{1}$ found no case where both A1 segments originated directly from one ICA, while noting 13 instances of bihemispheric ACA where branches of one ACA anastomosed with branches of the other. In our case, contralateral anastomosis between one ICA and ACA branches was present, and the A1 segment contralateral to the supplying ICA was not visualized. Whether an anatomically normal left A1 segment and the anterior communicating artery did not form (aplasia) or were fully formed but later occluded is not completely certain, since we recognized this component of the anomaly only from lack of filling on the angiogram. We hypothesize that either agenesis or flow impairment involving the contralateral normally situated A1 segment resulted in persistence of an embryonal A1 segment to supply the territory of the contralateral ACA. In this manner, ICA-to-ACA anastomoses may result from persistence of embryonal A1 segment arteries.

\section{REFERENCES}

1. Baptista AG. Studies on the arteries of the brain: II-The anterior cerebral artery: Some anatomic features and their clinical implications. Neurology 1963; 13: 825-835.

2. Dunker RO, Harris AB. Surgical anatomy of the proximal anterior cerebral artery. J Neurosurg 1976; 44: 359-367.

3. Gomes FB, Dujovny M, Umansky F, et al. Microanatomy of anterior cerebral artery. Surg Neurol 1986; 26: 129-141.

4. Friedlander RM, Oglivy CS. Aneurysmal subarachnoid hemorrhage in a patient with bilateral A1 fenestrations associated with an azygos anterior cerebral artery. Case report and literature review. J Neurosurg 1996; 84: 681-684.

5. Maurer J, Maurer E, Perneczky A. Surgically verified variations in the A1 segment of the anterior cerebral artery: report of two cases. J Neurosurg 1991; 75: 950-953.

6. Marinkovic S, Milisavljevic M, Marinkovic Z. Branches of the anterior communicating artery: Microsurgical anatomy. Acta Neurochir (Wien) 1990; 106: 78-85.

7. Nathal E, Yasui N, Sampei T, Suzuki A. Intraoperative anatomical studies in patients with aneurysms of the anterior communicating artery complex. J Neurosurg 1992; 76: 629-634.

8. Lasjaunias P, Berenstein A, Ter Brugge KG. Surgical neuroangiography....I Clinical vascular anatomy and variations. In: Lasjaunias P, Berenstein A, Ter Brugge KG, (Eds). 2nd ed. The Cranial Internal Carotid Artery Division. Berlin Heidelberg New York Tokyo: Springer-Verlag, 2001: 578-610. 